\title{
BENTUK LAIN TEOREMA VAN AUBEL PADA SEGITIGA
}

\author{
Wita Maywidia ${ }^{1}$, Mashadi $^{2}$, Sri Gemawati ${ }^{3}$ \\ ${ }^{1}$ FMIPA Universitas Riau dan SMA Alkaromah Aidarusy, witamaywidia25@gmail.com \\ ${ }^{2}$ FMIPA Universitas Riau, mashadi.mat@ gmail.com \\ ${ }^{3}$ FMIPA Universitas Riau, gemawati.sri@gmail.com
}

\begin{abstract}
In general the Van Aubel Theorem is constructed from any quadrilateral. Some authors have developed in triangles. In this paper the author develops another form of Van Aubel's theorem on triangles. The proofing process is done in a very simple way that uses congruence, similarity, concurrent and colinear. The result obtained are three pairs of sides that are parallel, equal in length and intersect perpendicular.
\end{abstract}

Keywords: Van Aubel's theorem, similarity, colinear

\begin{abstract}
ABSTRAK
Secara umum Teorema Van Aubel dikontruksi dari segiempat sebarang. Beberapa penulis telah mengembangkan dalam segitiga. Dalam tulisan ini penulis mengembangkan bentuk lain teorema Van Aubel pada segitiga. Proses pembuktiannya dilakukan dengan cara yang sangat sederhana yaitu menggunakan kekongruenan, kesebangunan, kekonkurenan dan kekolinearan. Hasil yang diperoleh adalah terdapat tiga pasang sisi yang sejajar, sama panjang dan berpotongan tegak lurus.
\end{abstract}

Kata kunci:Teorema Van Aubel, kesebangunan, kekolinearan

\section{PENDAHULUAN}

Teorema Van Aubel pertama kali dikemukan oleh Henri Van Aubel pada tahun 1878 [10]. Teorema Van Aubel dikontruksi dari segiempat sebarang, kemudian pada setiap sisi segiempat sebarang dibangun persegi, titik-titik potong diagonal persegi yang berlawanan dihubungkan sehingga terbentuk dua sisi sama panjang dan berpotongan tegak lurus (Gambar 1). 


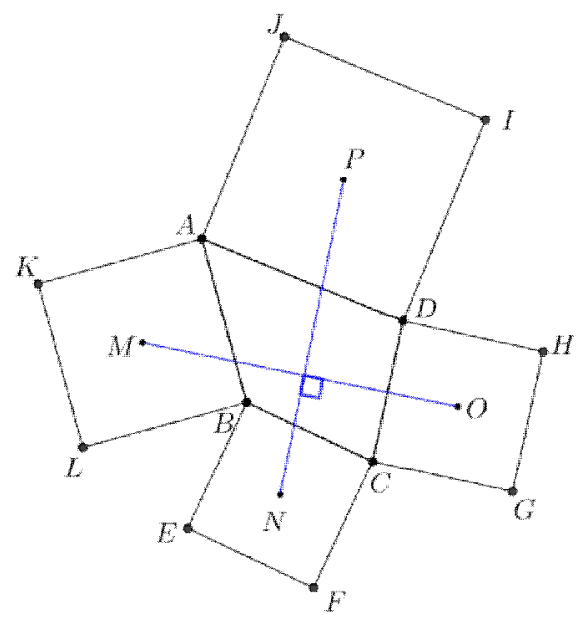

\section{Gambar 1.Ilustrasi teorema Van Aubel padasegiempat}

Beberapa pengembangan teorema Van Aubel pada segiempat antara lain [4, 6, 15] serta pengembangan lain juga dilakukan pada teorema Van Aubel yaitu dengan memulai kontruksi dari sebuah segitiga sebarang $[1,3]$. Teorema Van Aubel pada segitiga menyatakan bahwa, jika persegi $A C H I, A D E B$ dan $B F G C$ dengan titik potong diagonal $J, K$ dan $L$ pada sisi $A C, A B$ dan $B C$ pada $\triangle A B C$ maka sisi $J L=C K$ dan $J L$ tegak lurus $C K$ dinyatakan dengan $J L \perp C K$, diilustrasikan pada Gambar 2.

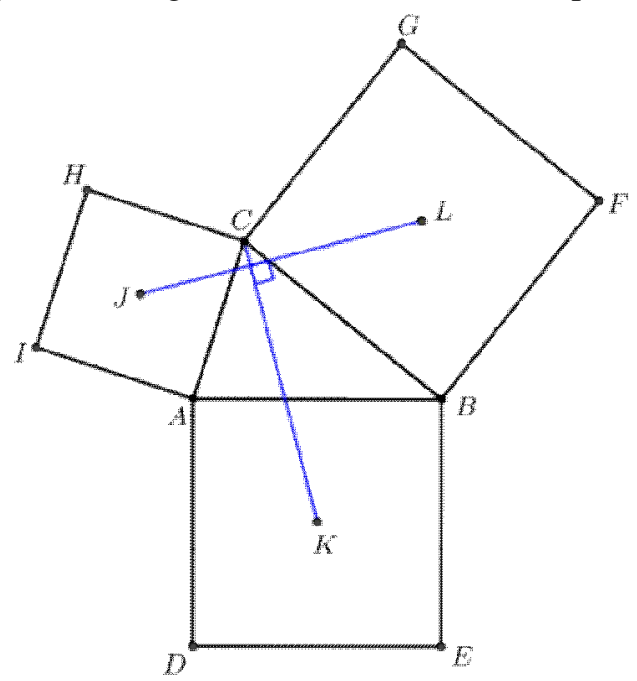

Gambar 2. Ilustrasi teorema Van Aubel padasegitiga

Berbagai konsep trigonometri aturan sinus dan kosinus dibahas dalam $[2,7,8]$, sedangkan beberapa konsep pembuktian kolinearan dan kekonkurenan terdapat pada $[5,13,14,16]$. Kemudian pada tulisan ini untuk membuktikan bentuk lain teorema Van Aubel pada segitiga dikerjakan dengan kekongruenan, kesebangunan, kekonkurenan dan kekolinearan. 
Pembuktian teorema Van Aubel bisa dijadikan pengayaan dalam mempelajari materi trigonometri di sekolah menengah atas sekaligus mengasah sejauh mana peserta didik bisa memanfaatkan pengetahuan yang dimilikinya pada materi lain seperti persegi dan kesebangunan.

Berdasarkan konsep teorema Van Aubel pada segitiga yaitu menemukan dua sisi yang sama panjang dan tegak lurus, maka penulis tertarik untuk menemukan bentuk lain teorema Van Aubel pada segitiga.

\section{Teorema Ceva, Teorema Menelaus, Segitiga Orthologic dan Teorema Van Aubel pada Segitiga}

\subsection{Teorema Ceva}

Teorema 1. Jika D, E, F masing-masing adalah titik pada sisi $B C, C A$ dan $A B$ pada $\triangle A B C$ maka garis $A D, B E$ dan $C F$ adalah kongkuren (bertemu disatu titik) jika dan hanya jika

$$
\frac{A F}{F B} \frac{B D}{D C} \frac{C E}{E A}=1
$$

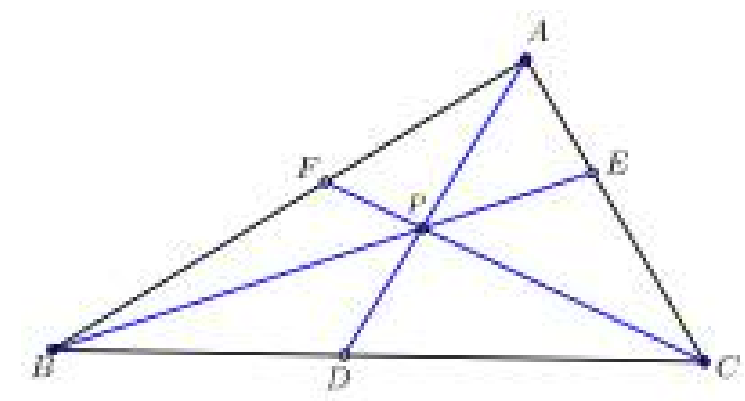

Gambar 3. Ilustrasi teorema Ceva pada segitiga

\subsection{Teorema Menelaus}

Teorema 2.Jika $D, E$ dan $F$ masing-masing terletak pada sisi $B C, C A$ dan $A B$ pada $\triangle A B C$ maka titik $D, E$ dan $F$ adalah segaris jika dan hanya jika

$$
\frac{A F}{F B} \frac{B D}{D C} \frac{C E}{E A}=-1
$$




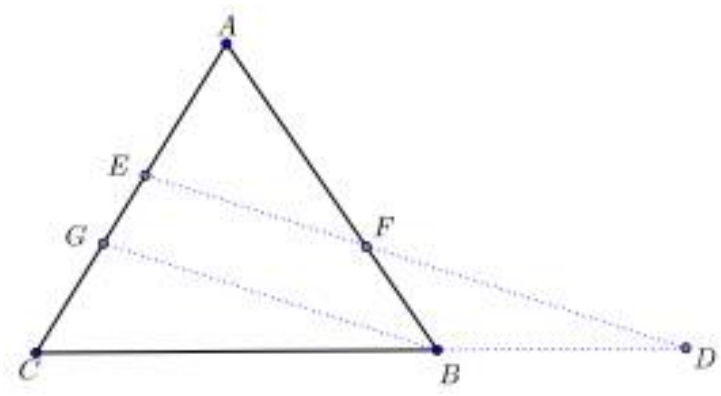

Gambar 4. Ilustrasi teorema Menelaus pada segitiga

\subsection{Segitiga Orthologic}

Definisi 3. $\triangle A B C$ dikatakan orthologic dengan $\triangle A_{1} B_{1} C_{1}$ jika garis tegak lurus yang ditarik dari titik $\mathrm{A}, \mathrm{B}$ dan $\mathrm{C}$ berturut-turut ke sisi $B_{1} C_{1}, C_{1} A_{1}$ dan $A_{1} B_{1}$ kongkuren.

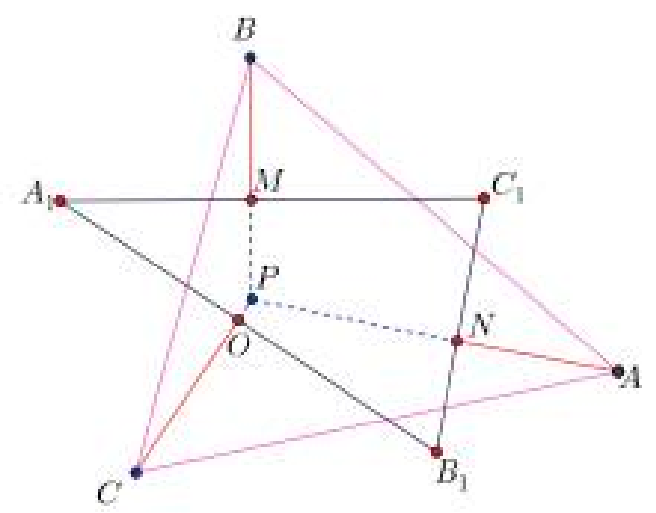

Gambar 5. Ilustrasi dua segitiga orthologic yang berpotongan

\subsection{Teorema Van Aubel pada Segitiga}

Teorema 4. Jika persegi $A B G F, B C I H$ dan $A C D E$ dengan titik potong diagonal $J, K$ dan $L$ pada sisi $A B, B C$ dan $A C$ pada $\triangle A B C$ maka sisi $J K=B L$ dan $J K \perp B L$. 


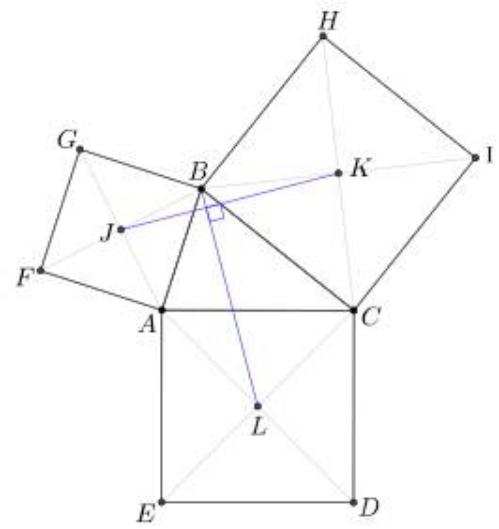

\section{Gambar 6. Ilustrasi teorema Van Aubel pada segitiga}

\section{Bentuk Lain Teorema Van Aubel pada Segitiga}

Beberapa bentuk lain teorema Van Aubel pada segitiga yang dibahas pada tulisan ini yaitu sebagai berikut:

Teorema 5. Pada sebarang segitiga $A B C$ dikontruksi persegi luar untuk tiap sisinya sehingga terbentuk persegi $A C H I, A D E B \operatorname{dan} B F G C$. Titik $P, Q, R, S, T$ dan $U$ secara berturut-turut merupakan titik tengah $A I, A D, E B, B F, G C$ dan $C H$. Titik $M, N$ dan $O$ secara berturut-turut merupakan titik tengah $I D, E F$ dan $G H$, maka $P S=M N$ dan $P S / / M N$.

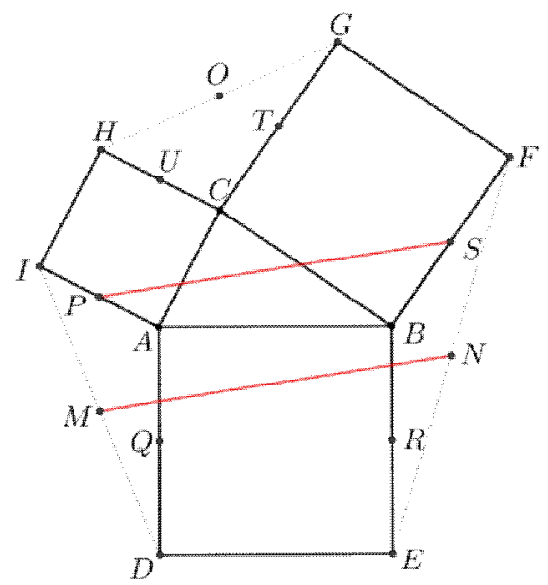

Gambar 7. Bentuk lain pertama Teorema Van Aubel pada segitiga Bukti: Akan dibuktikan $P S=M N$. Buat $\triangle P C A$ dan $\triangle S C B$. Jikapanjang $B C=a$, $A C=b, A B=c$ maka akan selalu berlaku $P C=\frac{1}{2} \sqrt{5} b, S C=\frac{1}{2} \sqrt{5} a$. Misal $\angle P C A$ adalah $\theta$, sehingga $\angle S C B=\theta$. Diilustrasikan pada Gambar 8 . 


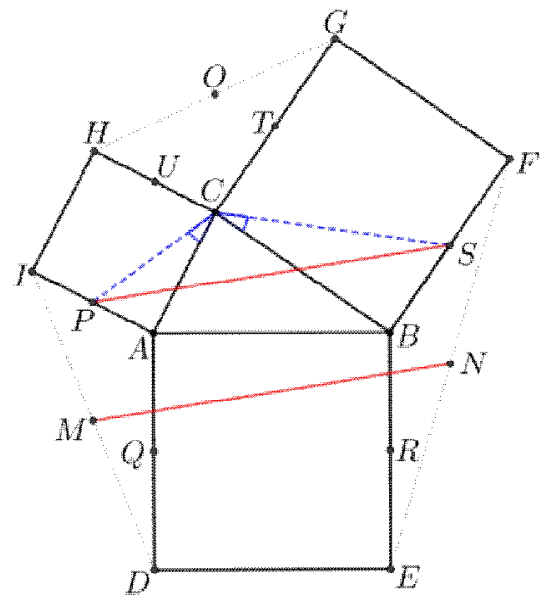

Gambar 8. Ilustrasi pembuktian panjang $P S$

Selanjutnya, akan ditentukan panjang $P S$ dengan menggunakan aturan cosinus. Pandang $\triangle P S C$, diperoleh

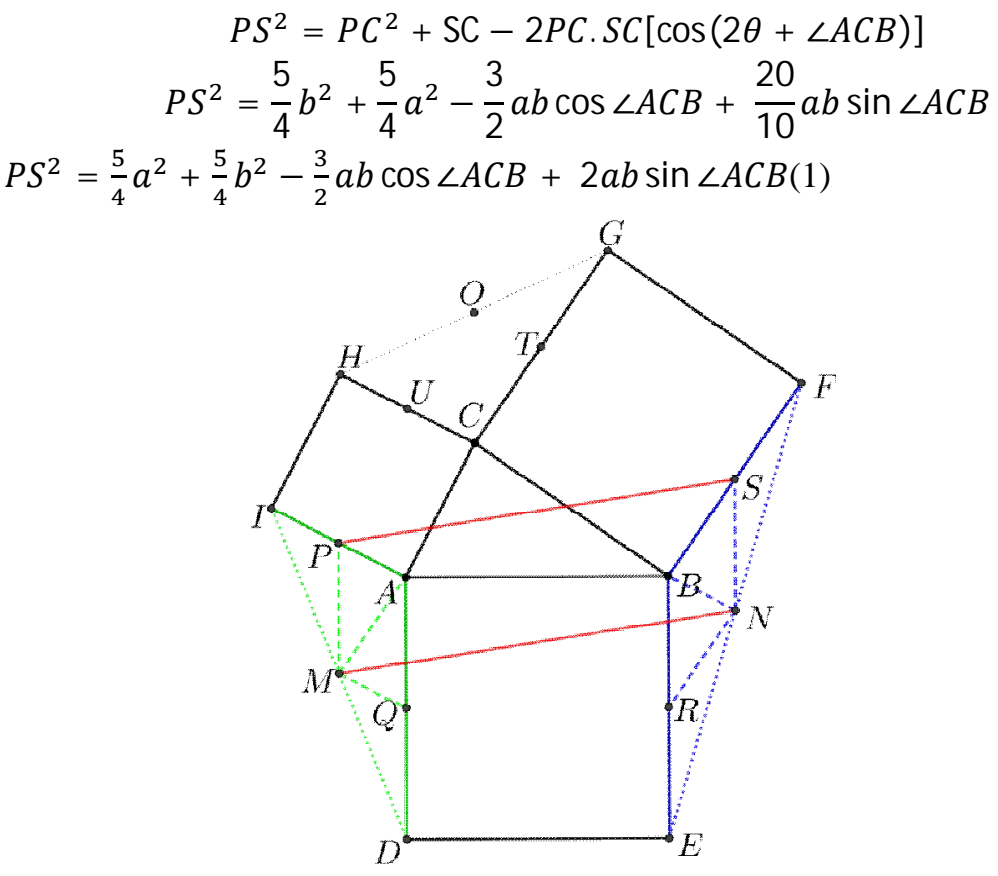

Gambar 9. Ilustrasi pembuktian $P S$ sejajar $M N$

Lalu, pandang $\triangle M P I$ dan $\triangle D A I$, diketahui $\frac{A P}{I A}=\frac{I M}{I D}=\frac{1}{2}, \angle P I M=\angle A I D$ (dipakai bersama) karena memenuhi syarat sisi-sudut-sisi, maka $\triangle M P I \sim \triangle D A I$. Sehingga berlaku

$$
P M=\frac{1}{2} c
$$

dengan menggunakan aturan cosinus pada $\triangle D A I$ diperoleh 


$$
\begin{gathered}
I D^{2}=A I^{2}+A D^{2}-2 \cdot A I \cdot A D \cos \angle D A I \\
I D^{2}=b^{2}+c^{2}-2 b c \cos \left(180^{\circ}-\angle C A B\right) \\
I D^{2}=b^{2}+c^{2}+2 b c \cos \angle C A B
\end{gathered}
$$

dari $\triangle D A I$ juga diketahui bahwa $A M$ adalah garis berat $\triangle D A I$, sehingga diperoleh

$$
\begin{gathered}
A M^{2}=\frac{1}{2} A I^{2}+\frac{1}{2} A D^{2}-\frac{1}{4} I D^{2} \\
A M^{2}=\frac{1}{2} b^{2}+\frac{1}{2} c^{2}-\frac{1}{4}\left(b^{2}+c^{2}+2 b c \cos \angle C A B\right) \\
\left.A M^{2}=\frac{1}{4} b^{2}+\frac{1}{4} c^{2}-\frac{2}{4} b c \cos \angle C A B\right) \\
A M^{2}=\frac{1}{4} a^{2} \\
A M=\frac{1}{2} a
\end{gathered}
$$

Disisi lain pandang $\triangle M D Q$ dan $\triangle I D A$, diketahui bahwa $\frac{D Q}{D A}=\frac{D M}{D I}=\frac{1}{2}$, $\angle M D Q=\angle I D A$ dipakai bersama), karena memenuhi syarat sisi-sudut-sisi, maka $\triangle M D Q \sim \triangle I D A$. Sehingga berlaku

$$
Q M=\frac{1}{2} b
$$

karena $A M=\frac{1}{2} a, Q M=\frac{1}{2} b$ dan $A Q=\frac{1}{2} c$ maka $\triangle Q A M$ sebangun dengan $\triangle$ $A B C$. Sehingga diperoleh $\angle Q A M=\angle A B C, \angle A M Q=\angle A C B$ dan $\angle M Q A=B A C$.

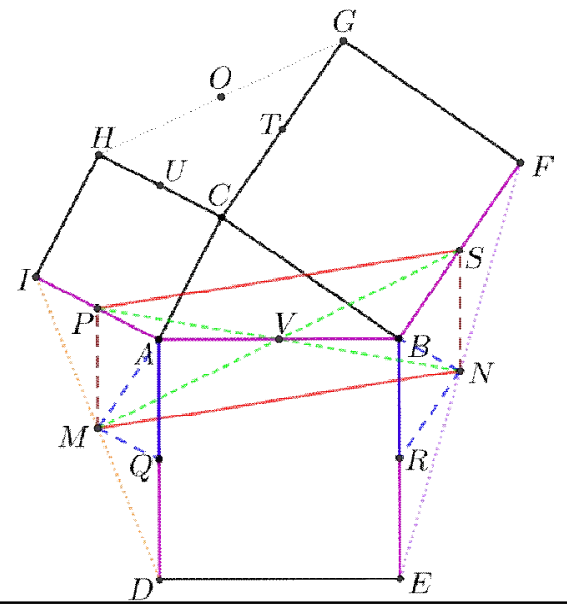

Gambar 10. Ilustrasi pembuktian $\triangle Q A M, \triangle B R N$ sebangun dengan $\triangle A B C$

Selanjutnya, kontruksi titik $V$ ditengah $A B$. Lalu, pandang $\triangle V A M \quad$ pada Gambar 10, diperoleh

$$
\angle V A M=90^{\circ}+\angle A B C
$$

dari $\triangle V B S$ diperoleh

$$
\angle V B S=90^{\circ}+\angle A B C
$$

karena $A M=B S=\frac{1}{2} a, A V=V B$ dan $\angle V A M=\angle V B S$ maka $\triangle V A M=\triangle V B S$ sehingga didapat bahwa 


$$
M V=V S
$$

Pandang $\triangle F S N$ dan $\triangle F B E$, diketahui $\frac{F S}{F B}=\frac{F N}{F E}=\frac{1}{2}$ dan $\angle N F S=\angle E F B$ (dipakai bersama), karena memenuhi syarat sisi-sudut-sisi, maka $\triangle F S N \sim \triangle F B E$. Sehingga berlaku

$$
S N=\frac{1}{2} c
$$

Selanjutnya, dengan menggunakan aturan cosinus pada $\triangle B E F$ diperoleh

$$
\begin{gathered}
E F^{2}=B F^{2}+B E^{2}-2 \cdot B F \cdot B E \cos \angle E B F \\
E F^{2}=B F^{2}+B E^{2}-2 \cdot B F \cdot B E \cos \left(180^{\circ}-\angle A B C\right) \\
E F^{2}=a^{2}+c^{2}+2 a c \cos \angle A B C
\end{gathered}
$$

Pada $\triangle F B E$ diketahui bahwa $B N$ adalah garis berat $\triangle B E F$, sehingga didapat

$$
\begin{gathered}
B N^{2}=\frac{1}{2} B F^{2}+\frac{1}{2} B E^{2}-\frac{1}{4} E F^{2} \\
B N^{2}=\frac{1}{2} a^{2}+\frac{1}{2} c^{2}-\frac{1}{4}\left(a^{2}+c^{2}+2 a c \cos \angle A B C\right) \\
B N^{2}=\frac{1}{4} a^{2}+\frac{1}{4} c^{2}-\frac{2}{4} a c \cos \angle A B C \\
B N^{2}=\frac{1}{4} b^{2} \\
B N=\frac{1}{2} b
\end{gathered}
$$

Pandang $\triangle N R E$ dan $\triangle F B E$ pada Gambar 10, diketahui $\frac{E R}{E B}=\frac{E N}{E F}=\frac{1}{2}$ dan $\angle R E N=\angle B E F$ (dipakai bersama) karena memenuhi syarat sisi-sudut-sisi, maka $\triangle N R E \sim \triangle F B E$. Sehingga berlaku

$$
R N=\frac{1}{2} a
$$

karena $B R=\frac{1}{2} c, B N=\frac{1}{2} b$ dan $R N=\frac{1}{2} a$ maka didapat $\triangle B R N$ sebangun dengan $\triangle A B C$. Sehingga diperoleh $\angle B R N=\angle A B C, \angle N B R=\angle B A C$ dan $\angle R N B=\angle A C B$.

Selanjutnya, pandang $\triangle N B V$ pada Gambar 6, diperoleh

$$
\angle N B V=90+\angle B A C
$$

disisi lain juga diketahui bahwa

$$
\angle P A V=90+\angle B A C
$$

karena $\angle N B V=\angle P A V, A V=V B$ dan $A P=B N$ sehingga dapat disimpulkan bahwa

$$
P V=V N
$$

Dari persamaan (2), (3), (4) dan (5) diperoleh bahwa

$$
P M=S N
$$

dan 
Selanjutnya dari persamaan (2), (3), (4), (5), (6) dan (7) diperoleh bahwa

$$
P S=M N
$$

artinya,

$$
M N^{2}=\frac{5}{4} a^{2}+\frac{5}{4} b^{2}-\frac{3}{2} a b \cos \angle A C B+2 a b \sin \angle A C B(9)
$$

dan

$$
\text { PS //MN }
$$

Berdasarkan persamaan (8) dan (10) maka terbuktilah teorema ini.

Akibat 6. Jika diketahui $M, N, O$ secara berturut-turut merupakan titik tengah $I D, E F, G H$ dan titik $P, Q, R, S, T$ danU secara berturut-turut adalah titik tengah $I A, A D, E B, B F, G C$ dan $C H$ maka $P M N S, R N O U$ dan $M Q T O$ adalah jajar genjang.

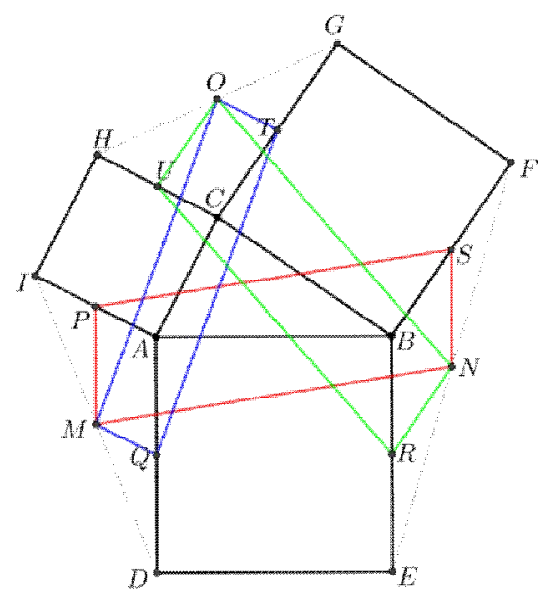

Gambar 11. Jajar genjang $P M N S, R N O U$ dan $M Q T O$

Bukti: Berdasarkan persamaan (3), (5), (6), (7), (8), (10) dan diketahui $\angle P M N+$ $\angle M N S=\angle N S P+\angle S P M=\angle S P M+\angle P M N=\angle M N S+\angle N S P=180 \quad$ (sudut dalam sepihak), juga diketahui $\angle P M N=\angle N S P$ dan $\angle S P M=\angle M N S$ (sudut-sudut yang berhadapan), dapat disimpulkan $P M N S$ adalah jajar genjang.

Langkah pembuktian yang sama berlaku untuk RNOU dan MQTO.

Teorema 7.Pada sebarang $\triangle A B C$ dikontruksi persegi luar untuk tiap sisinya sehingga terbentuk persegi $A C H I, A D E B, B F G C$ dan $J, K, L$ merupakan titik potong diagonalnya. Titik $M, N, O$ secara berturut-turut adalah titik tengah $I D, E F, G H$, maka $K O=M N \operatorname{dan} K O \perp M N$. 


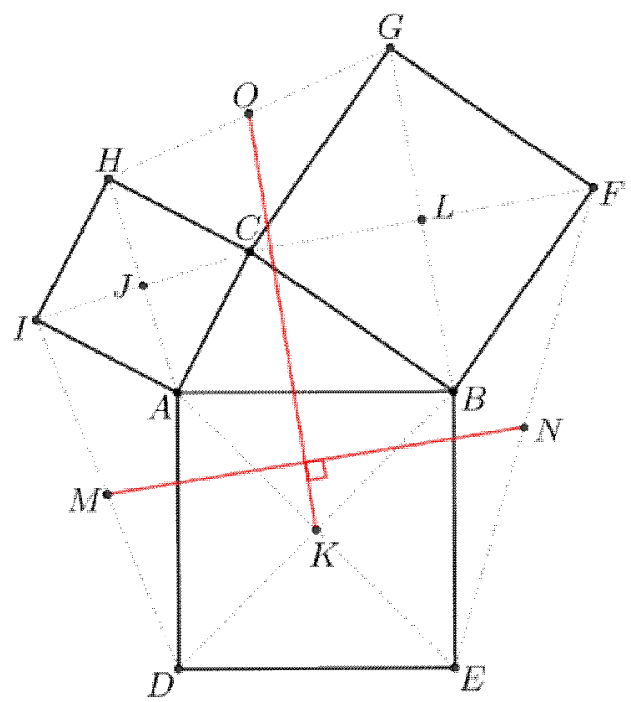

Gambar 12. Bentuk lain kedua Teorema Van Aubel padasegitiga

Bukti: Dari persamaan (9) diperoleh $M N^{2}=\frac{5}{4} a^{2}+\frac{5}{4} b^{2}-\frac{3}{2} a b \cos \angle A C B+$ $2 a b \sin \angle A C B$. Selanjutnya, akan ditentukan panjang $K O$. Buat $\triangle H K G$ seperti yang terlihat pada Gambar 13.

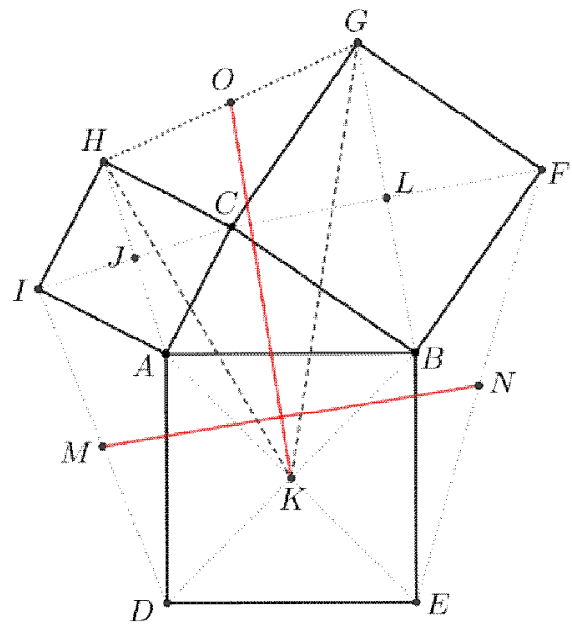

Gambar 13. Ilustrasi pembuktian $K O$

Diketahui $O$ adalah titik tengah $G H$, sehingga $K O$ merupakan garis berat $\triangle H K G$ dan panjang $K O$ dapat ditentukan dengan mengetahui panjang $H K, G K$ dan $H G$. Buat $\triangle H A K$ untuk memperoleh panjang $H K$ dan $\triangle K B G$ untuk menentukan panjang $G K$, seperti yang terlihat pada Gambar 14. 


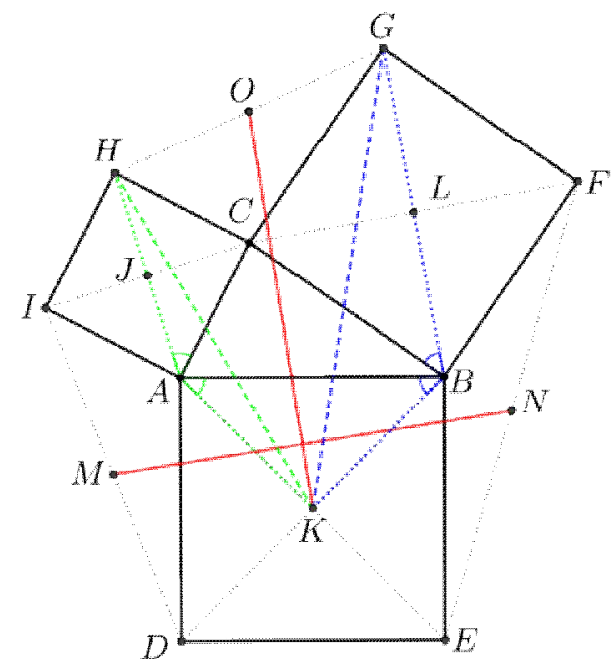

Gambar 14. Ilustrasi pembuktian $K O$ dengan bantuan $\triangle H A K$ dan $\triangle K B G$

dari $\triangle H A K$ diperoleh

$$
\begin{gathered}
H K^{2}=A H^{2}+A K^{2}-2 A H A K \cos \left(90^{\circ}+\angle B A C\right) \\
H K^{2}=(b \sqrt{2})^{2}+\left(\frac{c}{2} \sqrt{2}\right)^{2}-2(b \sqrt{2})\left(\frac{c}{2} \sqrt{2}\right) \cos \left(90^{\circ}+\angle B A C\right) \\
H K^{2}=2 b^{2}+\frac{1}{2} c^{2}+2 b c c \sin \angle B A C
\end{gathered}
$$

dari $\triangle K B G$ diperoleh

$$
\begin{gathered}
G K^{2}=B G^{2}+B K^{2}-2 \cdot B G \cdot B K \cos \left(90^{\circ}+\angle A B C\right) \\
G K^{2}=(a \sqrt{2})^{2}+\left(\frac{c}{2} \sqrt{2}\right)^{2}-2(a \sqrt{2})\left(\frac{c}{2} \sqrt{2}\right) \cos \left(90^{\circ}+\angle A B C\right) \\
G K^{2}=2 a^{2}+\frac{1}{2} c^{2}+2 b c \sin \angle B A C
\end{gathered}
$$

Setelah memperoleh panjang $H K$ dan $G K$ akan ditentukan panjang $H G$.

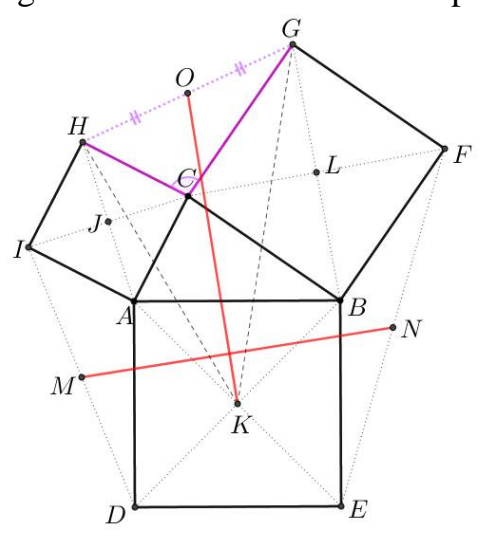

Gambar 15. Ilustrasi pembuktian $K O$ dengan bantuan $\triangle H C G$ 
Pandang $\triangle H C G$ pada Gambar 15, dengan menggunakan aturan cosinus diperoleh

$$
\begin{gathered}
G H^{2}=C G^{2}+\mathrm{CH}^{2}-2 C G \cdot C H \cos \left(180^{\circ}-\angle A C B\right) \\
G H^{2}=a^{2}+b^{2}-2 a b(-\cos \angle A C B) \\
G H^{2}=a^{2}+b^{2}+2 a b \cos \angle A C B
\end{gathered}
$$

$K O$ adalah garis berat $\triangle H K G$, berdasarkan teorema Garis Berat maka berlaku

$$
K O^{2}=\frac{1}{2} H K^{2}+\frac{1}{2} G K^{2}-\frac{1}{4} G H^{2}
$$

Selanjutnya, substitusi nilai persamaan (11), (12) dan (13) ke persamaan (14), sehingga diperoleh

$$
K O^{2}=\frac{3}{4} a^{2}+\frac{3}{4} b^{2}+\frac{2}{4} c^{2}+2 b c \sin \angle B A C-\frac{2}{4} a b \cos \angle A C B
$$

dari $\triangle A B C$ dengan menggunakan aturan cosinus pada $\angle \mathrm{C}$ diperoleh

$$
c^{2}=a^{2}+b^{2}-2 a b \cos \angle A C B
$$

serta dengan menggunakan aturan sinus pada $\triangle A B C$ diperoleh

$$
\sin A=\frac{a \sin C}{c}
$$

Dengan mensubstitusikan persamaan (16) dan (17) ke persamaan (15) maka didapat

$$
\begin{gathered}
K O^{2}=\frac{3}{4} a^{2}+\frac{3}{4} b^{2}+\frac{2}{4}\left(a^{2}+b^{2}-2 a b \cos \angle A C B\right)+2 b c \sin \left(\frac{a \sin C}{c}\right)- \\
\qquad \frac{2}{4} a b \cos \angle A C B \\
K O^{2}=\frac{5}{4} a^{2}+\frac{5}{4} b^{2}-\frac{3}{2} a b \cos \angle A C B+2 a b \sin \angle A C B
\end{gathered}
$$

Jadi, dari persamaan (9) dan (18) dapat disimpulkan bahwa

$$
K O=M N
$$

Selanjutnya, akan dibuktikan $K O \perp M N$. Langkah pertama adalah dengan membuat lingkaran dengan pusat $M$ dan jari-jari $M K$. Lalu, buat pula lingkaran yang berpusat di $N$ dengan panjang jari-jari $N K$ ( $K$ adalah titik potong diagonal persegi $A D E B$ dan juga berada pada lingkaran berpusat di $M$ dan $N$ ). Sehingga diperoleh titik $W$ yang berada pada lingkaran yang berpusat di $M$ dan $N$, seperti yang terlihat pada Gambar 16. 


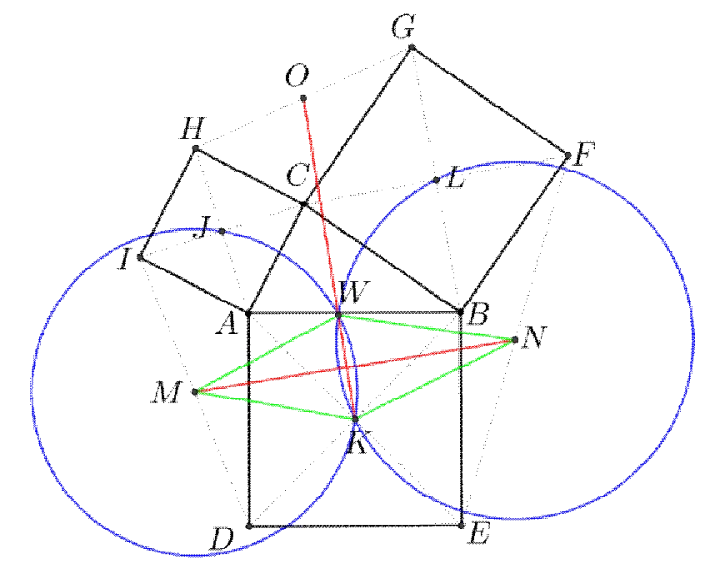

Gambar 16. Ilustrasi pembuktian layang-layang

Kemudian, pandang $\triangle K M W$, diketahui $M K=M W$, sehingga diperoleh $\triangle K M W$ adalah segitiga sama kaki dan

$$
\angle M K W=\angle M W K
$$

Lalu, pandang $\triangle K N W$, diketahui $N K=N W$, sehingga $\triangle K N W$ adalah segitiga sama kaki dan

$$
\angle N K W=\angle N W K
$$

Dari persamaan (20) dan (21) didapat

$$
\angle M K W+\angle N K W=\angle M W K+\angle N W K
$$

Oleh sebab itu, segiempat $M K N W$ adalah layang-layang dengan diagonalnya $W K$ dan $M N$ yang berpotongan tegak lurus di titik $X$. Diilustrasikan pada Gambar 17.

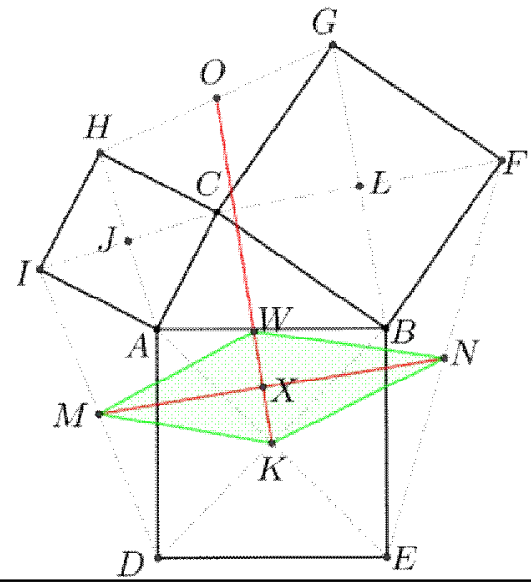

Gambar 17.Segiempat layang-layang $M K N W$

Kemudian akan ditunjukkan titik $K, W, O$ segaris. Perpanjang sisi $M K$ sehingga memotong sisi $B E$ dititik $M^{\prime}$. Perpanjang sisi $M^{\prime} W$ sehingga memotong sisi $M O$ 
dititik $W^{\prime}$. Sehingga membentuk $\triangle M W^{\prime} M^{\prime}$. Selanjutnya, misalkan titik $V$ pada $M M^{\prime}$, sedemikian sehingga garis $W^{\prime} V$ sejajar $O K$ dan juga sejajar $W K$. Diilustrasikan pada Gambar 18.

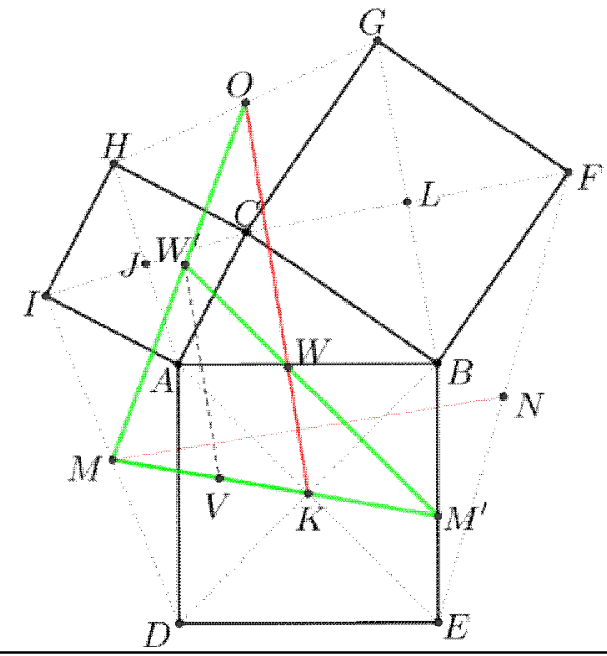

Pandang $\begin{gathered}\text { Gambar 18.Ilustrasi pembuktian titik } K, W, O \text { segaris } \\ \triangle W^{\prime} M V \text { dan } \triangle O M K, \quad \angle W^{\prime} M V=\angle O M K, \angle M W^{\prime} V \angle M O K,\end{gathered}$ sehingga $\triangle W^{\prime} M V \sim \triangle O M K$, yang mengakibatkan

$$
\frac{W^{\prime} O}{O M}=\frac{V K}{K M}
$$

Lalu, pandang $\triangle M^{\prime} W K$ dan $\triangle M^{\prime} W^{\prime} V, \angle W M^{\prime} K=\angle W^{\prime} M^{\prime} V, \angle M^{\prime} K W=$ $M^{\prime} V W^{\prime}$, sehingga $\Delta M^{\prime} W K \sim \Delta M^{\prime} W^{\prime} V$, yang mengakibatkan

$$
\frac{M^{\prime} W}{W W^{\prime}}=\frac{M^{\prime} K}{K V}
$$

Dari persamaan (23) dan (24) diperoleh

$$
\begin{aligned}
& \frac{M^{\prime} W}{W W^{\prime}} \frac{W^{\prime} O}{O M} \frac{M K}{K M^{\prime}}=\frac{M^{\prime} K}{K V} \frac{V K}{K M} \frac{M K}{K M^{\prime}} \\
& \frac{M^{\prime} W}{W W^{\prime}} \frac{W^{\prime} O}{O M} \frac{M K}{K M^{\prime}}=-1
\end{aligned}
$$

karena persamaan (25) memenuhi teorema Menelaus, maka titik $W$ ada di garis $O K$ atau titik $O, W, K$ segaris.

Berdasarkan pembuktian di atas, diperoleh bahwa $W K$ tegak lurus $M N$ dan $O, W, K$ segaris, maka

$$
K O \perp M N
$$

Berdasarkan persamaan (19) dan (26) maka terbuktilah teorema ini.

Akibat 8. Pada sebarang $\triangle \mathrm{ABC}$ dikontruksi persegi luar untuk tiap sisinya sehingga terbentuk persegi $A C H I, A D E B, B F G C$ dan $J, K, L$ merupakan titik potong diagonalnya. Titik $M, N$ dan $O$ secara berturut-turut merupakan titik tengah $I D, E F$ 
dan $G H$. Titik $P, Q, R, S, T$ dan $U$ secara berturut-turut adalah titik tengah $I A, A D, E B, B F, G C$ dan $C H$, makaKO = PS dan $K O \perp P S$.

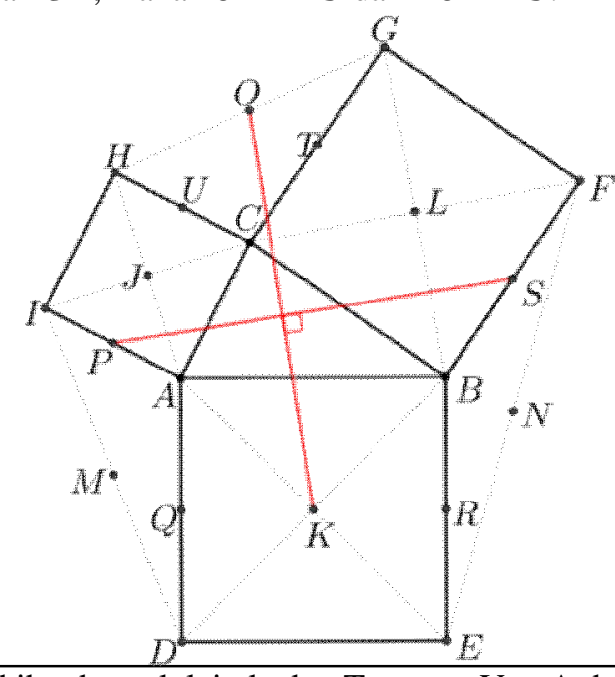

Gambar 19. Akibat bentuk lain kedua Teorema Van Aubel pada segitiga

Bukti:Berdasarkan persamaan (8) dan (19) jelas bahwa $K O=P S$. Lalu, dari persamaan (10) serta persamaan (26), jelas bahwa $K O \perp P S$. Sehingga terbukti $K O=P S \operatorname{dan} K O \perp P S$.

\section{KESIMPULAN}

Dari hasil pembahasan didapatkan beberapa antara lain terdapat bentuk lain dari teorema Van Aubel pada yaitu adanya tiga pasang garis yang sejajar dan sama panjang, sehingga menghasilkan tiga jajar genjang, serta terdapat tiga pasang garis yang tegak lurus dan sama panjang. Konsekuensi dari hal ini adalah terbentuknya tiga pasang garis yang tegak lurus dan panjang yang lain.

\section{REFERENSI}

[1] Alsina C. dan Nelsen R. B. Charming Proofs: A Journey into Elegant Mathematics. Washington DC: The Mathematical Association of America, 2010.

[2] Baharuddin A., Mashadi., Saleh H. dan Hasriati. Modifikasi Teorema Van Aubel pada Segitiga, Jurnal Matematics Paedagogic, Vol 7, 111-118, 2017

[3] Gardner M. Mathematical Circus. Washington DC:The Mathematical Association of America, 1992.

[4] Glaister P. A Van Aubel Theorem Revisited, Applied Probability Trust, 33-36, 2015. 
[5] Januarti P., Mashadi, Sri G. dan Hasriati. Some Result on Excircle of Quadrilateral, JP Journal of Mathematics Sciences, Vol14, 41-56, 2015.

[6] Krishna D. N. V. A New Consequence of Van Aubel's Theorem, Department of Mathematic, 1-9, 2016.

[7] Mashadi.Geometri Lanjut. Pekanbaru: Unri Press, 2015.

[8] Mashadi. Pengajaran Matematika. Pekanbaru: UR Press, 2016.

[9] Mulyadi., Mashadi., Habibis S. dan Hasriati. Pengembangan Teorema Van Aubel pada Segienam, Jurnal Mathematic Paedagogic, Vol 1, 119-128, 2017.

[10] Nishiyama, Y. The Beautiful Geometri theorem of Van Aubel, International Journal of Pureand Applied Mathematic, Vol1, 71-80, 2011.

[11] Patrascu I. dan Smarandache F. Pantazi's Theorem Regarding the Biorthological Triangles, Smarandache Nations Jaournal, Vol 1, 1-5, 2010.

[12] Patrascu I. dan Smarandache F. A Theorem about Simultaneous Orthological and Homological Triangles, Smarandache Nations Jaournal, Vol 1, 1-13, 2010.

[13] Valentika C., Mashadi. dan Sri G. The Development of Napoleon's Theorem on Quadrilateral with Congruence and Trigonometry, Bulletin of Mathematics, Vol 8, 97-108, 2016.

[14] Valentika C., Mashadi. dan Sri G. Development of Napoleon's Theorem on the Rectangles in Case of Inside Direction, International Journal of Theoretical and Applied Mathematics, Vol 3, 54-57, 2017.

[15] Villiers M. D.Generalizing Van Aubel Using Duality, Mathematic Magazine, Vol 4, 303-307, 2000.

[16] Zukrianto., Mashadi. dan Sri G. A Noncovex Quadrilateral and Semi Gergonne Points on It: Some Result and Analysis, Fundamental Journal of Mathematics and Mathematical Sciences, Vol 6, 111-124, 2016. 